\title{
iorhs
}

\section{Women's Emotional Experience to Covid 19 Social Constraints Influenced By Loneliness Feelings, Optimism and Negative Expectations}

\author{
Ognyan Koychev ${ }^{1}$ and Liliya Babakova ${ }^{2}$ \\ ${ }^{1}$ Plovdiv University “Paisii Hilendarski”, Plovdiv, Bulgaria \\ ${ }^{2}$ Academy of Music, Dance and Fine Arts, Plovdiv, Bulgaria
}

\begin{abstract}
.
The aim of the online study is to explore the effect of feelings of loneliness, optimism and negative expectations on negative emotional experience during a pandemic. 290 women from 20 to 75 years of age were examined. Toolkit: (1) author's questionnaire consisting of four subscales: negative emotional experience related to welfare certainty, negative emotional experience related to health, negative emotional experience related to personal control over the situation and negative emotional experience related to family relationships (Koychev \& Babakova, 2020); (2) an adapted version of the scale for social and emotional loneliness for adults (SELSA-S; DiTommaso et al., 2004) and (3) a scale for optimism and negative expectations (Velichkov \& Radoslavova, 2005). Applying linear regression analysis it was found that the negative expectations have the strongest effect on the negative emotional experience related to welfare certainty $(\beta=0.256 ; p \leq 0.001)$. Health effects are influenced by social loneliness $(\beta=0.204 ; p=0.004)$ in combination with negative expectations $(\beta=0.206$; $\mathrm{p}=0.001)$. The emotional experience connected with family relations is influenced by the feeling of emotional loneliness $(\beta=0.312 ; p=0.001)$ combined with negative expectations $(\beta=0.133 ; p=0.023)$. The female negative expectations reveal to be a good predictor for the negative emotional experience related to personal control over the situation $(\beta=0.232 ; p=$ 0.001). The negative expectations combined with emotional loneliness impose higher influence on the personal control over the situation of women over 35 years $(\beta=0.607 ; p=$ $0.001)$.
\end{abstract}

Keywords: loneliness, optimism, negative expectations, emotional experience, pandemic social constraints

\section{Introduction}

The situation related to the pandemic in the last year has greatly changed the world with "forced isolation". The social distance and limitations associated with COVID-19 have greatly influenced people's perceptions of stability, balance and comfort zone. Chronicles of events, various media versions of the disease, rumors, panic and fear of the future are 


\section{iorhs}

\section{4th International Conference On Research In HUMANITIES \& SOCIAL SCIENCES}

associated with uncertainty and unpredictability in the future. In "forced isolation" a person falls into a state of uncertainty, which is even more stressful than the knowledge of the actual expected negative consequences (Sidyacheva \& Zotova, 2020).

\subsection{Loneliness and negative emotional experience}

Halford et al. found that social distance was one of the main measures used to prevent coronavirus, but "this approach can have harmful side effects, such as loneliness and exacerbation and exacerbation of existing mental illness, which in turn are suicidal factors." (Halford et al., 2020).

There is much evidence in the psychological literature pointing to other destructive functions of loneliness on psychological well-being and health. For example, it is also a predictor of unhealthy behaviors (Newall et al., 2012) such as smoking (Theeke, 2010), increased cardiovascular resistance and increased systolic blood pressure (Hawkley et al., 2010), impaired mental health and cognitive functions (Cacioppo \& Hawkley, 2009), hospitalization (Löfvenmark, et al. 2009), and mortality (Shankar et al., 2011). Loneliness has been identified as a risk factor for depressive symptoms in both cross-sectional studies (Nolen-Hoeksema \& Ahrens, 2002) and longitudinal studies (Heiniken \& Kauppinen, 2004). Loneliness is considered to be more significant for women especially the elderly in causing mental health problems like emotional distress and depression (Bhawana Singh \& Kiran, 2013).

\subsection{Optimism, negative expectations and individual emotional experience.}

The positive role of optimism as a cognitive construct has been reported in the work of Carver and Scheier (2010). They point out that optimistic people make an effort to achieve their goals, and people with a pessimistic attitude often give up their efforts to achieve them. The authors conclude that there is a relationship between optimism and indicators of psychological and physical health.

Duy and Yildiz (2017) prove the mediating role of self-esteem in the relationship of optimism with subjective well-being. Research has also shown that not all forms of optimism affect well-being equally and that negative expectations can lead to depression and feelings of invulnerability to anxiety (Kleiman et al., 2015).

According to Hecht (2013), people's tendency to optimism or pessimism is explained by the fact that optimism and pessimism are associated with different hemispheres of the cerebral cortex. He believes that high self-esteem, the tendency to focus on the positive aspects of the situation, as well as the optimistic belief in the future are related to the physiological activity in the left hemisphere. The tendency to focus on negative assessment and exaggerate its significance, low self-esteem, as well as a pessimistic view of the future are associated with neurophysiological processes in the right hemisphere.

\subsection{Lonelines and optimism in women's emotional experience.}

Studying female college students and young nuns Neto and Baros observed that optimism correlated negatively with loneliness and they concluded that less optimistic girls might not be successful ennough in making sustainable relations with close ones and thus they fall in loneliness experience (Neto \& Barros, 2003). Ben-Zur found out negative correlation 


\section{iorhs}

\section{4th International Conference On Research In HUMANITIES \& SOCIAL SCIENCES}

between loneliness and optimism studying individuals with different marital status. Her research showed that well-being was positively contributed by optimism and negatively contributed by loneliness in all individuals independent from their marital status (Ben-Zur, 2012). Examining divorcee women Mishra and Mishra confirmed the tendency that optimism has been positively related to well-being while loneliness correlates negatively with the same variable (Mishra \& Mishra, 2020).

\section{Online study of female negative emotional experince in relation to loneliness, optimism and negative expectation during pandemic.}

\subsection{Method}

The purpose of the present study was to examine how feelings of loneliness, optimism, and negative expectations affect female negative emotional experience during a pandemic.

\subsubsection{Target group}

290 women have been examined in april and may 2020. $43.7 \%$ of them were 20 to 35 years of age, 53,9 \% were between 36 and 65 years and 2,4\% over 65 years of age. The prevailing part of the female subjects $(86 \%)$ was highly educated having Bachelor or Master Degree and the rest of the women (14\%) had a high school educational level. More than half of the participants in the study $(58,3 \%)$ were having full time paid jobs. The rest were part time paid or retired.

\subsubsection{Toolkit}

(1) author's questionnaire consisting of four subscales: negative emotional experience related to welfare certainty ( $\alpha=0.867)$, negative emotional experience related to health $(\alpha=$ $0.884)$, negative emotional experience related to personal control over the situation $(0.863)$ and negative emotional experience related to family relationships $(\alpha=0.877)$ (Koychev \& Babakova, 2020);

(2) an adapted version of the scale for social and emotional loneliness for adults (SELSAS; DiTommaso et al., 2004), containing three subscales: social loneliness, emotional loneliness and intimate-relational loneliness. The scale has been adapted for Bulgarian cultural context by Aleksandrova (Aleksandrova, N., 2015);

(3) a scale for optimism and negative expectations (Velichkov \& Radoslavova., 2005).

The study had been conducted online. Data were processed using SPSS statistical software, version 21. Descriptive and statistical methods were used: descriptive statistics, mean analysis, multivariate analysis of variance, regression analysis and cluster analysis.

Results

The comparative analysis of the mean values of the "Negative emotional experience", "Loneliness", "Optimism and negative expectations" scales gives an opportunity to differentiate the age variability according to the above parameters (Tab. 1).

Table 1. Comparative analysis of the mean values on the scales "negative experience", "loneliness" and "optimism and negative expectations" by "age" factor 


\section{iorhs}

4th International Conference On Research In

HUMANITIES \& SOCIAL SCIENCES

\begin{tabular}{|c|c|c|c|c|c|c|}
\hline Variable & Age & $\mathrm{N}$ & M & $\sigma$ & $\begin{array}{l}\text { Student's T- } \\
\text { test }\end{array}$ & $\mathrm{P}$ \\
\hline & $\begin{array}{c}\text { early } \\
\text { adulthood }\end{array}$ & 128 & 17.3594 & 6.66609 & 2.019 & 0,004 \\
\hline Welfare certainty & $\begin{array}{c}\text { middle } \\
\text { adulthood }\end{array}$ & 158 & 15.8797 & 5.72441 & 1.987 & \\
\hline \multirow{2}{*}{ Health } & $\begin{array}{c}\text { early } \\
\text { adulthood }\end{array}$ & 128 & 13.3047 & & .027 & \multirow[t]{2}{*}{0,218} \\
\hline & $\begin{array}{l}\text { middle } \\
\text { adulthood }\end{array}$ & 158 & 13.2911 & 4.00048 & .027 & \\
\hline & $\begin{array}{c}\text { early } \\
\text { adulthood }\end{array}$ & 128 & 8.4297 & 4.63755 & 1.411 & 0,159 \\
\hline Personal relations & $\begin{array}{l}\text { middle } \\
\text { adulthood }\end{array}$ & 158 & 7.6899 & 4.21387 & 1.397 & \\
\hline & $\begin{array}{c}\text { early } \\
\text { adulthood }\end{array}$ & 128 & 20.8281 & 7.22213 & 1.217 & 0,100 \\
\hline Personal control & $\begin{array}{l}\text { middle } \\
\text { adulthood }\end{array}$ & 158 & 19.8354 & 6.54710 & 1.205 & \\
\hline & $\begin{array}{c}\text { early } \\
\text { adulthood }\end{array}$ & 126 & 11.2143 & 5.89998 & -1.438 & 0,368 \\
\hline Social loneliness & $\begin{array}{l}\text { middle } \\
\text { adulthood }\end{array}$ & 158 & 12.2658 & 6.29368 & -1.449 & \\
\hline & $\begin{array}{c}\text { early } \\
\text { adulthood }\end{array}$ & 126 & 9.2460 & 6.35445 & 1.428 & 0,014 \\
\hline Emotional loneliness & $\begin{array}{l}\text { middle } \\
\text { adulthood }\end{array}$ & 158 & 8.2975 & 4.83947 & 1.386 & \\
\hline & $\begin{array}{c}\text { early } \\
\text { adulthood }\end{array}$ & 126 & 16.9048 & 10.24611 & 2.348 & 0,155 \\
\hline Romantic loneliness & $\begin{array}{r}\text { middle } \\
\text { adulthood }\end{array}$ & 156 & 14.1731 & 9.26259 & 2.323 & \\
\hline & $\begin{array}{c}\text { early } \\
\text { adulthood }\end{array}$ & 128 & 39.9531 & 7.11753 & -.649 & 0,299 \\
\hline Optimism & $\begin{array}{l}\text { middle } \\
\text { adulthood }\end{array}$ & 158 & 40.5253 & 7.63807 & -.654 & \\
\hline & $\begin{array}{c}\text { early } \\
\text { adulthood }\end{array}$ & 128 & 19.2422 & 5.27921 & .013 & 0,686 \\
\hline Negative expectations & $\begin{array}{l}\text { middle } \\
\text { adulthood }\end{array}$ & 158 & 19.2342 & 5.15884 & .013 & \\
\hline
\end{tabular}

Table 1 shows that there are statistically significant differences on the scale "Welfare Certainty" and the scale "Emotional loneliness". Women in early adulthood are more likely to 


\section{iorhs}

\section{4th International Conference On Research In HUMANITIES \& SOCIAL SCIENCES}

experience negative feelings related to welfare certainty than women over 35 years of age. Also, younger women are at greater risk of experiencing emotional loneliness, i.e. experiencing loneliness in their family, lack of understanding and support from loved ones.

The more intense welfare worries of the younger women were probably due to the fact of the beginning of their career development and their early stage of building their professional identity. Several possibilities may reason this assumption: 1. Frequent workplace changes that affect income sustainability; 2. Beginners higher risk of redundancy; 3. Planning or going into maternity leave. Each of these possibilities or their accumulation might raise the worries about the welfare sustainability during pandemic period.

In the same time the figures of the age variations in the "Negative feelings experienced in connection with welfare certainty" scale reveal a gradual decreasing of older women's concerns about their financial problems $(\mathrm{F}=1,790 ; \mathrm{p}=0,115)$.

The tendency that financial security concerns gradually decrease with women's age growth is shown on Figure 1. Over the years and with the accumulation of work experience, women have the opportunity to get a permanent job, which allows them to stay longer and provide them with more stable finances that create higher welfare certainty.

Figure 1. ANOVA on the scale "Negative feelings experience related to welfare certainty" scale and the "age" factor.

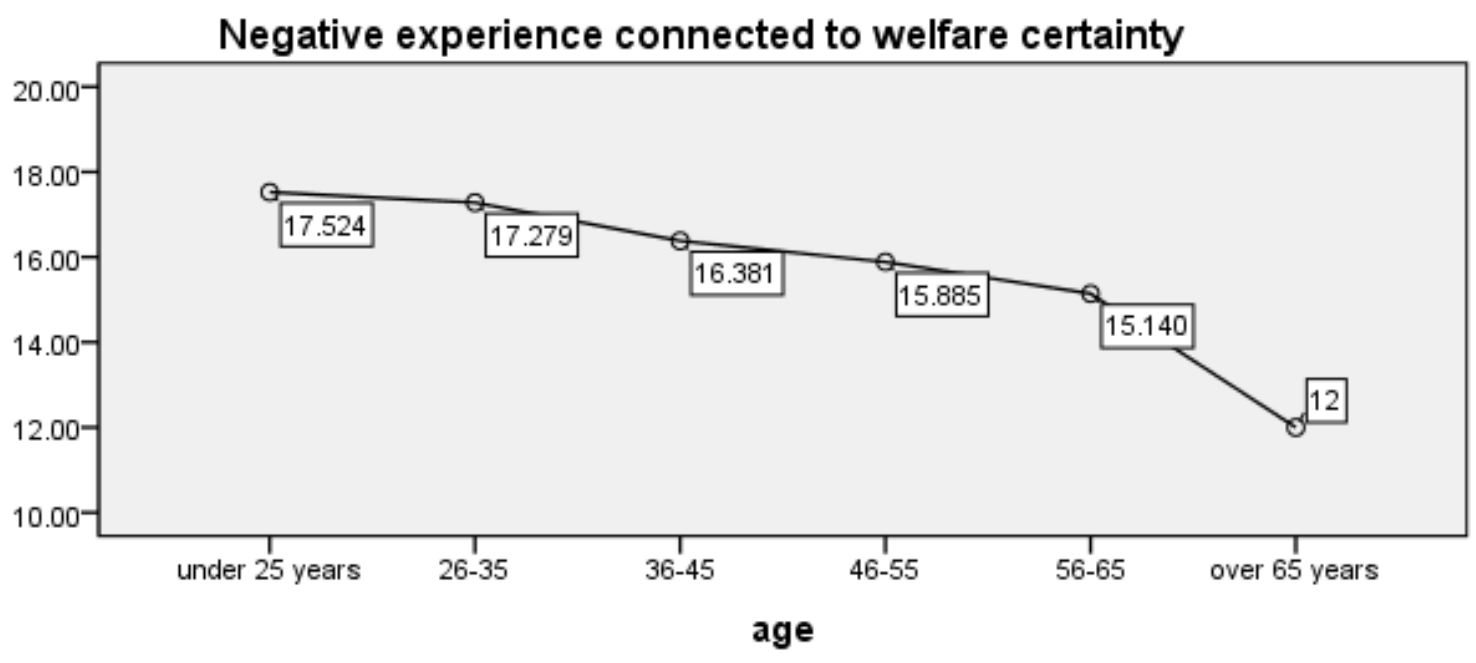

Younger women seem at greater risk of experiencing emotional loneliness than older women as shown on Tab. 1. The feeling of lack of understanding and support from family members among younger women may be due to the fact that many of them have not yet started their own family or are just starting one. Lack of intergenerational continuity can also provoke an experience of emotional loneliness in younger women.

By linear regression analysis it was found that women's negative expectations had the strongest impact on the emotional experience related to welfare certainty $(\beta=0.256$; $\mathrm{p} \leq 0.001)$. This trend did not apply to women under the age of 25 , and also to women between 56-65 years, where there was another trend. The oldest group of women experiencing social loneliness was most vulnerable to material security experiences. $(\beta=0.485 ; p=0.014)$. For the group of women between 36-45 years, it is characteristic that in addition to negative 


\section{iorhs}

\section{4th International Conference On Research In HUMANITIES \& SOCIAL SCIENCES}

expectations, positive expectations also negatively affect the emotional experience related to welfare certainty $(\beta=-0.313 ; p=0.024)$.

Health worries and fears were most strongly affected by social loneliness $(\beta=0.204 ; \mathrm{p}=$ $0.004)$ in combination with negative expectations $(\beta=0.206 ; p \leq 0.001)$. This trend is most common in women between $36-45$ years of age.

Negative emotional experience related to family relationships was influenced primarily by emotional loneliness $(\beta=0.312 ; p \leq 0.001)$ and negative expectations $(\beta=0.133 ; p=0.023)$. In the age group of 26 and 35 however, there was a reversed tendency of women's optimism to decrease negative feelings connected with family relations. Negative expectations were also a predictor for negative emotional experience related to personal control over the situation $(\beta=0.232 ; \mathrm{p} \leq 0.001)$, with a tendency for middle-aged women (46-55 years) to have emotional loneliness $(\beta=0.607 ; p \leq 0,001)$.

Figure 2. Model summarizing the relationships between negative emotional experience during a pandemic, feelings of loneliness and optimism / negative expectations in the examined group of adult women.

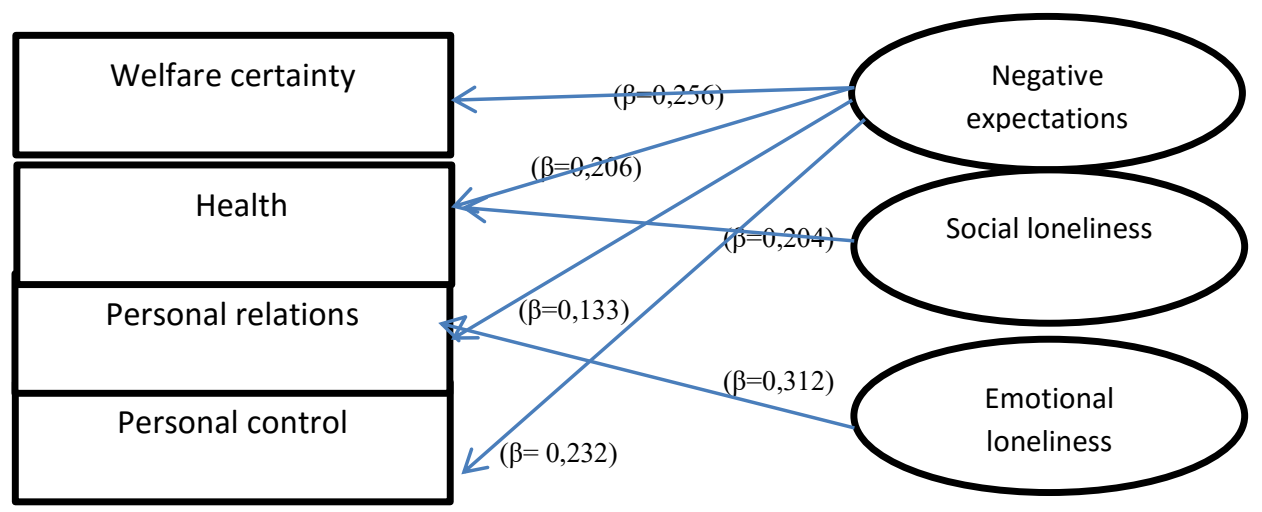

$R^{2}=0,090$

$R^{2}=0,088$

$R^{2}=0,164$

$R^{2}=0,126$

Fig. 2 presents a model summarizing the relationships between negative emotional experience during a pandemic, feelings of loneliness and optimism / negative expectations in the examined group of adult women. The model shows that negative expectations, social loneliness and emotional loneliness were the most significant predictors of negative emotional experience during a pandemic. Women's negative expectations significantly affect the experience of negative feelings related to welfare certainty $(\beta=0.256)$, health $(\beta=0.206)$, as well as personal control $(\beta=0.232)$. Feeling of social loneliness was a predictor of experiencing health concerns $(\beta=0.256)$. The feeling of lack of support from friends, acquaintances or colleagues leads to worries related to their health or that of loved ones. Feeling of emotional loneliness was a predictor of experiencing anxiety related to personal relationships, i.e. when there is misunderstanding or alienation in the family, most women in the sample report worries that family problems, quarrels or misunderstandings with the spouse, conflicts with family members may increase during a pandemic. 


\section{iorhs}

\section{4th International Conference On Research In HUMANITIES \& SOCIAL SCIENCES}

To understand specific age variations of the examined construct relationships, a cluster analysis was performed. Women in early adulthood 20-35 years of age and women in middle and late adulthood 36-45 years of age were compared. The dendrogram on the left shows a general picture of construct relationships in the women group between 36-65 years of age. There are two main clusters: one includes negative feelings related to personal relationships, emotional loneliness and social loneliness; the other cluster includes negative feelings related to welfare certainty, health concerns, feeling of lack of personal control over the situation and negative expectations. The feeling of lack of understanding and support from family, friends and acquaintances most often leads to worries related to relationships between relatives and acquaintances, fear of conflict in the group of the older women. This in turn leads to a feeling of romantic loneliness. In this age group, the negative emotional experience connected with personal relationships was largely related to the feeling of loneliness in general. Negative emotional experience related to health and lack of control over the situation, i.e. all those events that cannot be controlled by older women, were associated with negative expectations.

Figure 3. Data cluster analysis
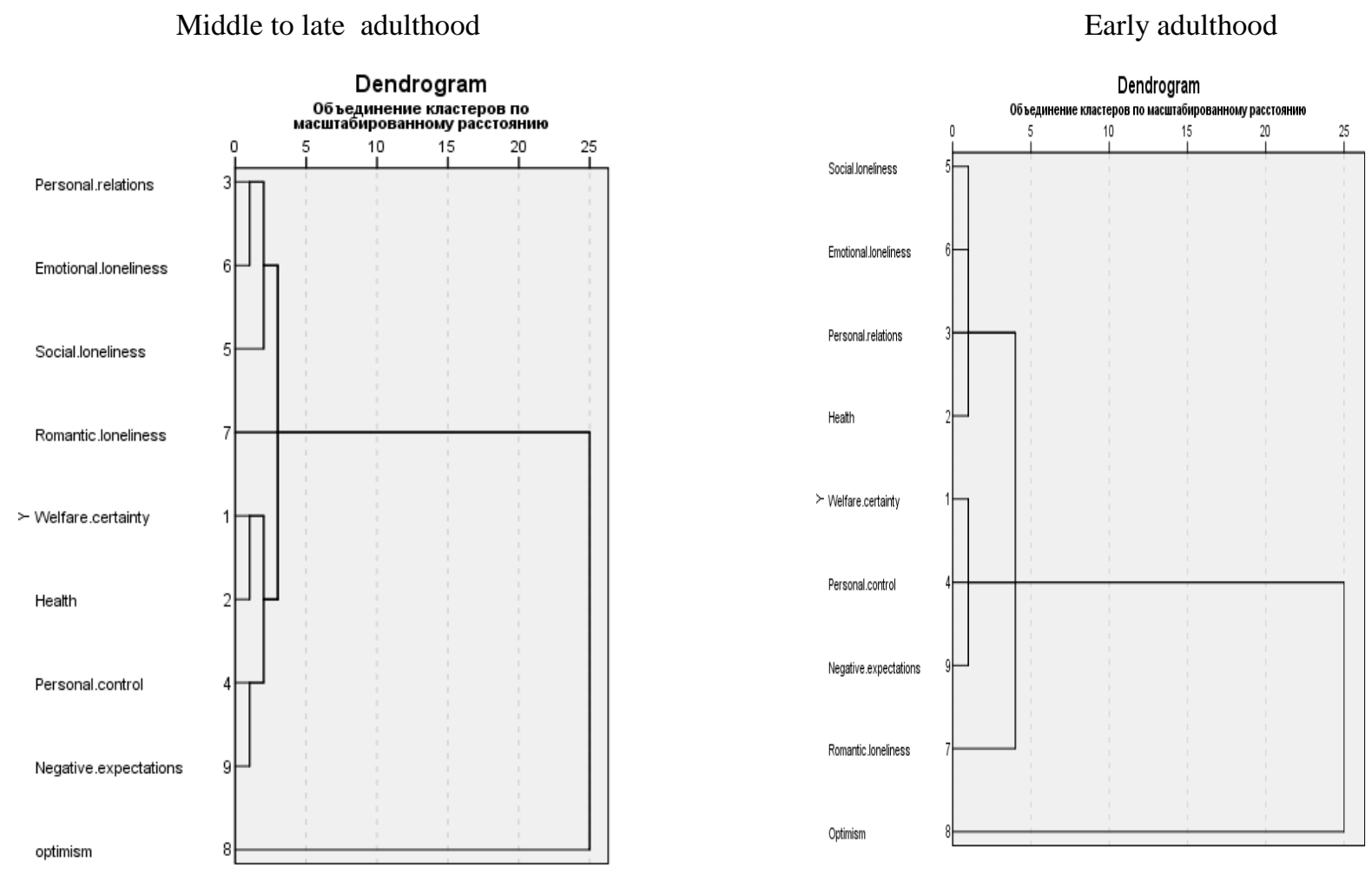

The dendrogram on the right shows a generalized picture of the connections between negative experiences - loneliness and optimism / negative expectations in younger women 


\section{iorhs}

\section{4th International Conference On Research In HUMANITIES \& SOCIAL SCIENCES}

(up to 35 years). Here the cluster structure is slightly different than in the group of older women. Loneliness was associated with negative emotional experience connected with personal relationships, but this also includes health concerns. Unlike older women, younger women experience a lack of support from friends, acquaintances, family and partner as a threat to their health or that of their loved one, which is mainly related to the fact that if something happens to them during a health pandemic, no one can help them. Similarly to the women in middle and late adulthood, the women in their early adulthood who have negative expectations tend to experience a lack of control over the situation, as well as a threat to their financial and material well-being.

\section{2}

Discussion

How women react to the pandemic social restraint and which are mediators to the raising negative feelings like fears, worries, concerns, anger and discontent? It seems that women differ in their negative emmotional experience due to variables like age, loneliness feelings optimism and negative expectations. The data provided in this study is not a generally valid description of the fimale emotional experience because of the reseaech design and procedure. (1) The online form probably provoked participants who are active in the net, i.e. a group with a specific communnication culture. (2) The education level of the wommenn in the study is very high. (3) As Aleksandrova has pointed out the low educational level relates with lonrliness and high education 1 level may even be a defense to loneliness (Aleksandrova, 2017). In the same time some of the derived tendencies in this study correspond to a hypothetical model of the connections between optimism and loneliness described by BenZur. According to this model high loneliness and high pessimism may be a result of third factors as neuroticism and different stressful events (Ben-Zur, 2015). This means that the correlations between high negative expectation, high social and emotional loneliness and worries about health and personal relations may be mediated by pandemic crisis or by additional personality factors

The examined group consists of only Bulgarian women. The peculiarities of the target group create certain limitations in interpretating and transfering of the results and the conclusions.

\section{Conclusion}

The present study found that negative expectations and feelings of loneliness are predictors of individual negative feelings provoked by social constraints during a pandemic in adult women.

The exammined women in early adulthood are more likely to experience anxiety related to their welfare certainty than older women. They also face a greater threat of experiencing emotional loneliness. However, with age, this trend gradually decreases.

Women who are pessimistic in their attitudes (having negative expectations) run the risk of experiencing worries related to their welfare certainty, health and personal control over situations. 


\section{iorhs}

\section{4th International Conference On Research In HUMANITIES \& SOCIAL SCIENCES}

Those female subjects who experience social loneliness are more likely to feel healthrelated worries, and those who feel lonely with their family and loved ones are at risk of negative emotions about their personal relationships.

Older and single women are more likely to experience negative emotions about personal relationships with their loved ones and acquaintances during a pandemic, while younger and single women tend to feel worries and concerns both about their personal relationships and their health.

Women's pessimism runs the risk of experiencing worries related to welfare certainty, health and personal control.

Those who experience social loneliness are more likely to feel health-related worries, and those who feel lonely with their family and loved ones are at risk of negative emotions about their personal relationships.

\section{Acknowledgment}

This paper is an output of the joint Bulgarian-Russian science project "Loneliness Versus Independence in the Life Cycle: Perspectives and Insights from Bulgaria and Russia".

\section{References}

Aleksandrova, N., Александрова, Н. (2015). Малка книжка за голямата самота. Изд. „Проф. Петко Венедиков“", София

Velichkov, A., \& Radoslavova, М., Величков, А., Радославова, М. (2005) „Метод за оценка на оптимизъм и негативни очаквания“, в: Радославова М., Величков $A$. Методи за психодиагностика, стр. 27-32, ИК Пандора Прим, София

Ben-Zur, H. (2012) „Loneliness, optimism, and well-being among married, divorced and widowed individuals“, in The Journal of Psychology: Interdisciplinary and Applied, 146, 1-2, pp. 23-36

Ben-Zur, H. (2015) „Optimism and lonellines. Literature review and explanatory models“ in Sha'ked, E. \& Rokach A. Adressing Loneliness. Coping, Prevention and Clinical Interventions, Routledge, Taylor \& Francis Group, 2015, pp. 155-170

Bhawana Singh, \& Kiran, U. V. (2013) „Loneliness among elderly women“, in International Journal of Humanities and Social Science Invention, Volume 2, Issue 1, pp. 1-5

Cacioppo, J. T., \& Hawkley, L. C. (2009). „Perceived social isolation and cognition“, in Trends in Cognitive Sciences, 13, pp. 447-454.

Sidyaceva, N., \& Zotova, L., Сидячева, Н., Зотова, Л. (2020). “Ситуация вынужденной самоизоляции в период пандемии: психологический и академический аспекты. Современные наукоемкие технологии", Педагогические науки, № 5, стр. 218-225 


\section{iorhs}

\section{4th International Conference On Research In HUMANITIES \& SOCIAL SCIENCES}

DiTommaso, E., Brannen, C., \& Best, L. (2004). "Measurement and validity characteristics of the short version of the social and emotional loneliness scale for adults", in Educational and Psychological Measurement, 64, pp. 99-119.

Halford, E.A., Lake, A.M., Gould, M.S. (2020) "Google searches for suicide and suicide risk factors in the early stages of the COVID-19 pandemic". PLOS ONE 15(7): e0236777. https://doi.org/10.1371/journal.pone.0236777

Hawkley, L., Thisted, R., Masi, C., \& Cacioppo, J. (2010). "Loneliness Predicts Increased Blood Pressure: 5-Year Cross-Lagged Analyses in Middle-Aged and Older Adults", in Psychology and Aging, Vol. 25, No. 1, pp. 132-141

Heikkinen, R., \& Kauppinen, M. (2004). "Depressive symptoms in late life:A 10-year followup", in Archives of Gerontology and Geriatrics, 38, pp. 239- 250

Koychev, O., \& Babakova, L., Койчев, О., Бабаков,а Л. (2020) Влияние на оптимизма, негативните очаквания и чувството за самота върху индивидуалните преживявания, свързани със социалните ограничения по време на пандемична криза, в Матанова В. (ред.) Ментализация и клинична практика, стр. 289-297, ИК СТЕНО, Варна

Löfvenmark, C., Mattiasson, A. C., Billing, E., \& Edner, M. (2009). "Perceived loneliness and social support in patients with chronic heart failure", in European Journal of Cardiovascular Nursing, 8, pp. 251-25

Mishra, S., \& Mishra, P. C. (2020) „Experience of loneliness and optimism as a predictors of psychological well being in divorcee women“, in International Research Journal of Management Sociaology \& Humanity, Vol. 11, Issue 9, pp. 11-17

Neto, F., \& Barros, J. (2003) „Predictors of loneliness among students and nuns in Angola and Portugal", in The Journal of Psychology: Interdisciplined and Applied, 137, 351-362

Newall, N. E. G., Chipperfield, J. G., Bailis, D. S., \& Stewart, T. L. (2012). “Consequences of Loneliness on Physical Activity and Mortality in Older Adults and the Power of Positive Emotions", in Health Psychology, 32 (8), pp. 921-924

Nolen-Hoeksema, S., \& Ahrens, C. (2002). "Age differences and similaritiesin the correlates of depressive symptoms", in Psychology and Aging, 17, pp. 116-124.

Shankar, A., McMunn, A., Banks, J., \& Steptoe, A. (2011). "Loneliness, Social Isolation, and Behavioral and Biological Health Indicators in Older Adults", in Health Psychology, Vol. 30, No. 4, pp. 377-385

Theeke, L. A. (2010). "Sociodemographic and health-related risk for loneliness and outcome differences by loneliness status in a sample of U.S. older adults", in Research in Gerontological Nursing, 3, pp. 113-125 